\title{
Litterfall, decomposition and nutrient release patterns of different tree species in Taran Taran district of Punjab, India
}

\author{
S. Rani ${ }^{1}$, D.K. Benbi ${ }^{2}$, A. Rajasekaran ${ }^{3 *}$ and S.K. Chauhan ${ }^{4}$ \\ ${ }^{1}$ Himalayan Forest Research Institute, Panthaghati, Shimla- 171009 (Himachal Pradesh), INDIA \\ ${ }^{2}$ Department of Soil Sciences, Punjab Agricultural University, Ludhiana-141004 (Punjab), INDIA \\ ${ }^{3}$ Institute of Forest Genetics \& Tree Breeding, Coimbatore-641002, (Tamil Nadu), INDIA \\ ${ }^{4}$ Department of Forestry and Natural Resources, Punjab Agricultural University, Ludhiana-141004 (Punjab), INDIA \\ *Corresponding author. Email: a.rajsekaran@gmail.com
}

Received: October 07, 2015; Revised received: May 09, 2016; Accepted: July 10, 2016

\begin{abstract}
The present investigation was attempted to assess the leaf litter production, decomposition rate and amount of major nutrient return in Populus deltoides, Eucalyptus tereticornis, Tectona grandis and Pyrus pyrifolia based agroforestry land use systems in Taran Taran district which falls in the north western agro-climatic zone of the Punjab state, India. The litter production in selected tree species was quantified using litter traps and decomposition pattern of leaf litter was investigated by litter bag technique. Litterfall in the selected tree species varied significantly ( $5 \%$ level of significance) during different months of the study period. Among the four species, $P$. deltoides exhibited highest leaf litter production (7.8 tons/ha) followed by $T$. grandis (1.83 tons/ha) and E. tereticornis (1.77 tons/ha) whereas, lowest leaf litter production was observed in $P$. pyrifolia $(0.34$ tons/ha). The present study also showed that temperature as compared to rainfall play a significant (5\% level of significance) role in litter decomposition. In case of $P$. pyrifolia, $P$. deltoides and T. grandis decomposition take place 100 per cent, 98 per cent and 99 per cent respectively after 10 months whereas in E. tereticornis 87.7 per cent leaf decomposed after 10 months. The nutrients percentage through litter fall was maximum of nitrogen $(2.27 \%)$ followed by potassium (1.90 \%) and phosphorous $(0.32 \%)$. Maximum and minimum N input through leaf litter was in $P$. deltoides $(2.27 \%)$ and $P$. pyrifolia $(1.15 \%)$. The $\mathrm{K}$ input $(\%)$ was maximum in leaves of $T$. grandis $(0.32)$ and minimum in $E$. tereticornis $(0.21)$. The maximum input of $\mathrm{P}(\%)$ through leaf litter was in $P$. deltoides (1.90) whereas, minimum value was observed in $E$. tereticornis (1.27). Tree based agroforestry land use systems improve soil nutrient status as compared to traditional wheat and paddy based land use systems under this region of Punjab. Therefore tree based land use systems need to be promoted over the traditional field crops for realizing better environmental benefits in this region.
\end{abstract}

Keywords: Litter production, Litter decomposition, Nitrogen, Phosphorous, Potassium, Tree species

\section{INTRODUCTION}

Tree plantations have many beneficial interactions with the surrounding environment such as watershed protection and improve the organic matter and nutrient status of the soil through the production of litter. The rate of litter fall and decomposing of litter is, however, largely governed by climatic factors and structural composition of litter. The extent to which litter influence soil fertility and plant growth is determined mainly by their biochemical quality, decomposition rate, time of nutrient release and crop nutrient demand. Tree, produce a considerable quantity of litterfall in the autumn season which starts in July and continuous till December. The litterfall is an important input for replenishment of organic matter and return of nutrients to the soil. It is one of the most important pathways for maintaining the soil fertility of different land use systems. The amount and pattern of litterfall varies with the type of species, growth and age, tree density, canopy characteristics, intercrops, season, etc (Moshin et al., 1996, Singh 1998, Bhardwaj et al., 2001). To show the importance of leaf litters in terms of carbon and nitrogen storage and cycling in different land use systems, it was essential to quantify the production of leaf litters under different canopy of trees. The type of plant litter may dramatically affect the type of soil organic matter formed (Swift et al., 1979). The quantity of nutrients released under different tree based land use systems is known to be dependent on the quality of biomass accumulated. Decomposition of leaf litter is a sequential process whereby complicated organic compounds are broken into simpler substances, releasing nutrients as byproduct of their breakdown (Yadav and Malanson 2007).

Taran Taran district of Punjab which falls in the north western agro-climatic zone of the Punjab state is well known for different tree based land use systems along traditionally grown field crops. Over the years the farmers have developed their own different land use systems integrating with fruits crops, field crops and forest tree species. These developed land use systems needs to be tested for their litter production, rate of decomposition 
and nutrient release. Further, information on nutrient release, litter production and decomposition of tree based land use system is also meager in different parts of Punjab (Singh 2009; Dhillon et al., 2012; Singh and Sharma, 2012). Therefore, the present investigation reports (i) leaf litter production of different tree species (ii) decomposition rate (iii) and amount of macronutrients like nitrogen $(\mathrm{N})$, potassium $(\mathrm{K})$, and phosphorus $(\mathrm{P})$ release from leaf litter in selected agroforestry land uses systems in Taran Taran district of Punjab.

\section{MATERIAL AND METHODS}

The study was conducted in Populus deltoids (Poplar), Eucalyptus tereticornis (Eucalyptus), Tectona grandis (Teak) and Pyrus pyrifolia (Hard Pear) based land use systems in Chabal Kalan village, Taran Taran district of the Punjab state, India. The experimental sites lie within $31^{\circ} 05^{\prime}$, and $31^{\circ} 30^{\prime} 05^{\prime \prime}$ North latitude and $74^{\circ} 30^{\prime}$ and $75^{0} 15^{\prime} 05^{\prime \prime E}$ East longitudes. This district is primarily under agriculture (82\% of the total area) and the plantations and orchards also form part of agricultural practice carried out in this area. The highest number of orchards in this district is of pears. There are four seasons in a year namely the cold season from November to March, hot season from April to June, south west monsoon season from the last week of June to the middle of September and the post monsoon season from September till the beginning of November. During cold season, a series of western disturbances affect the climate of the district. During the summer months i.e. from April to June, weather is very hot, dry and uncomfortable. The weather becomes humid and cloudy during July to September. Mean minimum and maximum air temperatures during April to September were $4.4-43^{\circ} \mathrm{C}$ (Figure 1). Mean annual precipitation of $472 \mathrm{~mm}$, most of it falling from July to September.

Leaf-litter collection: Five year old broad-leaved species such as Populus deltoides, Eucalyptus tereticornis, Tectona grandis and thirty year old fruit tree namely Pyrus pyrifolia which are growing under different agroforestry land use systems were selected for estimation of leaf litter fall. Total litter fall was estimated using litter traps (Tripathi and Singh 1992; Pandey 1999). Six traps (1m $\mathrm{x} 1 \mathrm{~m}$ size) with three replications per tree were placed randomly under the selected tree species. Out of six traps, one trap around the tree trunk and rest were placed around the tree ( 6 traps $\times 3$ replicates $\times 4$ species $=72$ litter traps). Litter from traps was collected at fifteen days interval for seven months. Fresh weight of the samples was taken with the help of digital balance. Samples were oven dried separately to a constant weight at $80^{\circ} \mathrm{C}$. The litter fall biomass was calculated by adding the oven dried weight of all the samples collected at different time.

Assessment of litter decomposition: Decomposition pattern of leaf litter was investigated by litter bag technique (Pandey et al., 2007). Mature senesced leaves were collected separately from all the four tree species and oven dried. A total of 176 litter bags ( $15 \times 15 \mathrm{~cm}$ size, 1 $\mathrm{mm}$ mesh) containing $15 \mathrm{~g}$ oven dried leaves for each site were prepared and placed randomly on the plough layer $(10-20 \mathrm{~cm})$ of the cultivated fields. Bags were stapled all along the sides at $5 \mathrm{~cm}$ intervals to allow the ease of macro fauna, but even the absence of large arthropods and earthworms cannot be ruled out (Kaushal et al., 2005). Consequently there could be underestimation of the litter decomposition rates. Four bags from each set were recovered randomly at monthly intervals from January 2014 to November 2014 till the completion of decomposition. The residual litter was brought to the laboratory and washed with water to remove the soil particles and then oven dried at $60^{\circ} \mathrm{C}$ to constant weight. Loss of dry matter in the decomposing litter was estimated by estimating the weight loss at monthly intervals. Relationship of weight loss was established with climatic variables with the help of regression analysis viz., temperature and rainfall.

Nutrient analysis of leaf litter: Triplicate leaf samples were collected from all the selected tree species for nutrient analysis. Matured and fully expanded leaves free from any type of disease and insect attack were plucked, and then washed with distilled water. The washed leaf samples were air dried for 2-3 days then dried in a hot air oven at $60^{\circ} \mathrm{C}$ for $24 \mathrm{hr}$ for complete drying. The dried samples were crushed in pestle and mortar and sieved through 72 mesh size and kept in polythene bags for nutrient analysis.

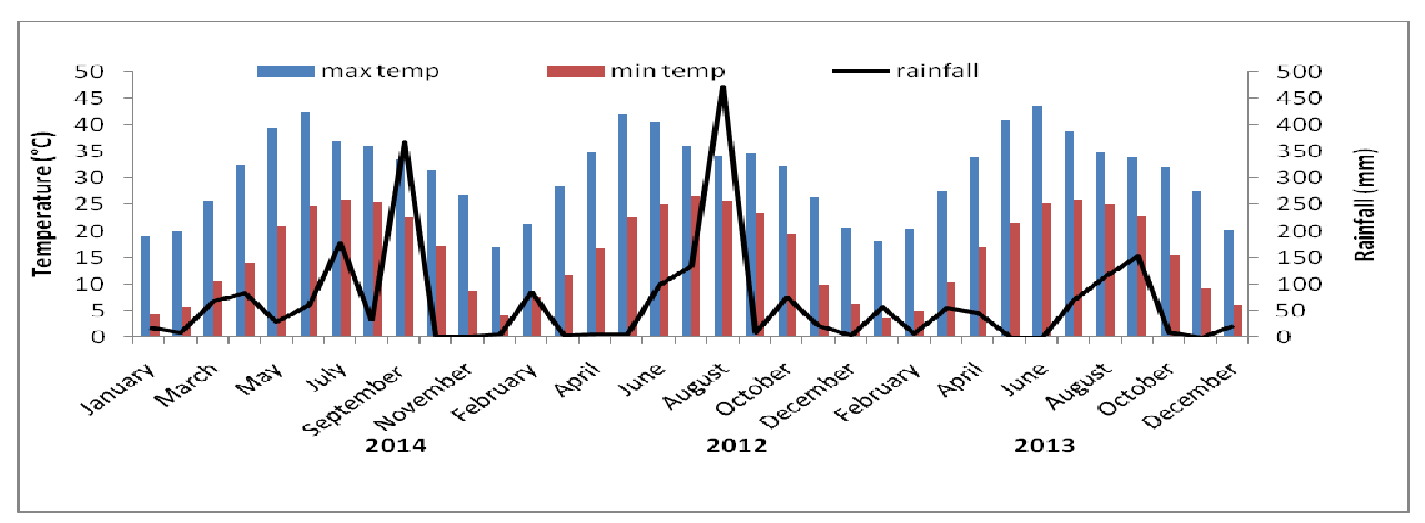

Fig. 1. Meteorological data of the Taran Taran district. Source: www.Tu.Tempo.net. 
Nitrogen: Plant material (0.5 g) was digested in concentrated $\mathrm{H}_{2} \mathrm{SO}_{4}$ with digestion mixture consisting $\mathrm{K}_{2} \mathrm{SO}_{4}$, $\mathrm{CuSO}_{4}, \mathrm{Se}$ and $\mathrm{HgO}$. After digestion, the extract obtained was analyzed for $\mathrm{N}$ using a micro-Kjeldhal assembly following Jackson (1973).

Phosphorus and potassium: The plant samples were digested using di acid $\left(3 \mathrm{HNO}_{3}: 1 \mathrm{HClO}_{4}\right)$ according to the procedure detailed by Piper (1966). The $\mathrm{P}$ in the digests was estimated using spectro-photometer by VandoMolybdo phosphoric acid method (Spark et al., 1996) and $\mathrm{K}$ content was analyzed with the help of flame photometer (Pratt 1982).

Nutrient return through litterfall: Nutrient return (tons/ ha) is calculated by nutrient concentration which is present in leaf portion (\%) multiplied by quantity of litterfall (Bhat and Jan, 2010).

Statistical analysis: The data generated from the present investigation was statistically analyzed using ANOVA and regression analysis was used to test the relationship of weight loss of litter with climatic variables especially temperature and rainfall as per Gomez and Gomez (1984). Mean separation was done with the Critical Dif-

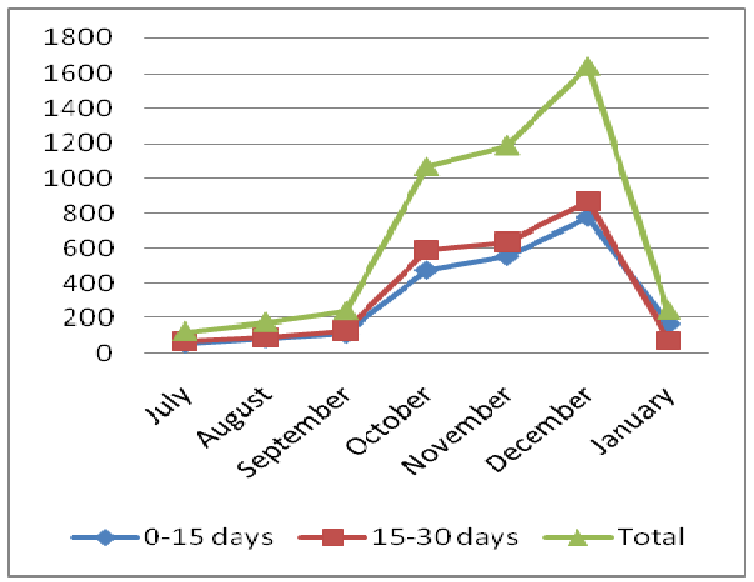

(a)

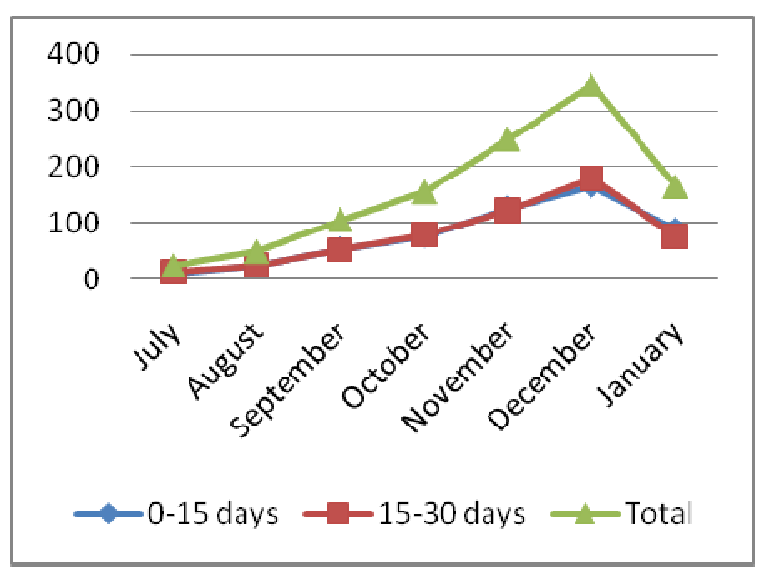

(c) ference (CD) test at 5\% level of significance.

\section{RESULTS AND DISCISSION}

Leaf litterfall: Litterfall in the selected tree species varied significantly (5\% level of significance) during different months of the study period. Shedding of leaves in poplar and teak initiated in the month of July and continued till January. Amongst the different months, the litterfall was significantly higher (5\% level of significance) after October and continue till December month. Mean monthly leaf litterfall of all the four tree species; $P$. deltoides, $E$. tereticornis, T. grandis and P. pyrifolia are shown in Fig. 2 . There was marked variation in the amount of leaf litterfall across season and tree species. All the four species had different pattern of leaf litterfall, due to different canopy and different seasonal fluctuations. $P$. deltoides shed maximum leaves after the September month and continues till December, whereas minimum leaves shed occurred under $P$. pyrifolia. During the present study, the highest litterfall production recorded for $P$. deltoides $(7.8$ tons/ha) under agri-silviculture land use system, followed by $T$. grandis (1.83 tons/ha), E. tereticornis (1.77 tons/ha)

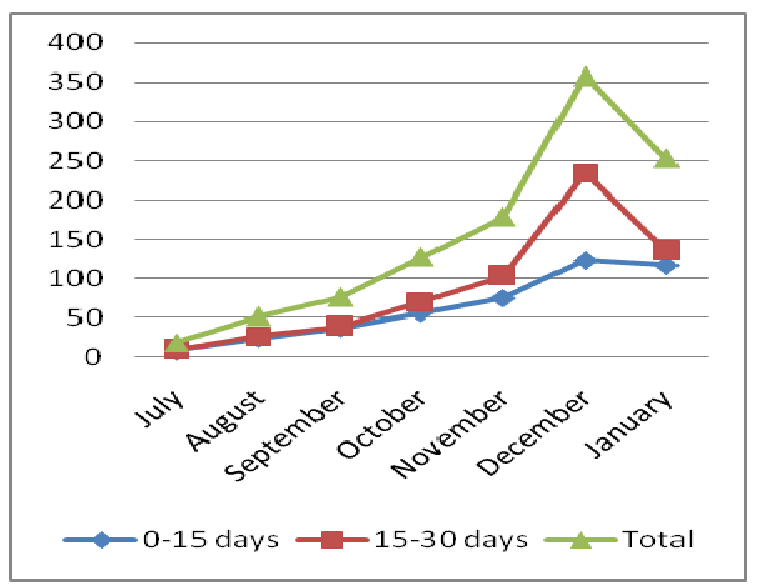

(b)

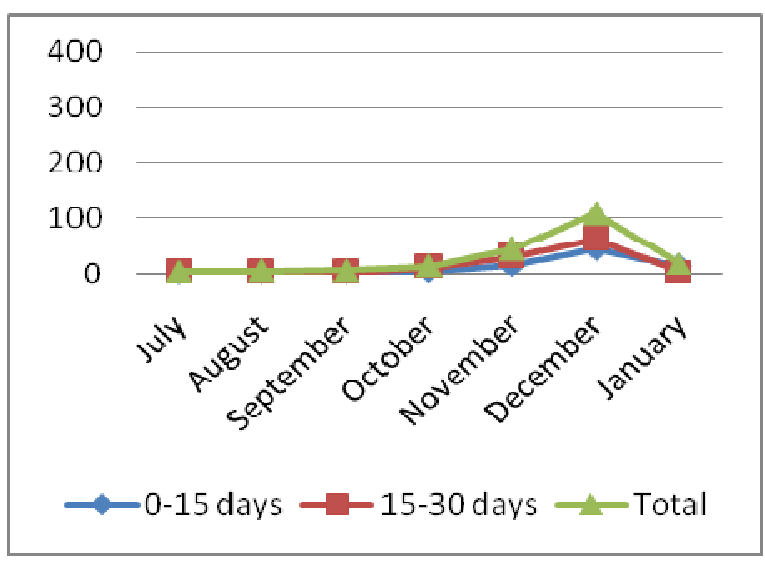

(d)

Fig. 2. Monthly share of litterfall (grams/month) of different tree species- (a) P.deltoides $(b)$ E.tereticornis $\quad(c)$ T.grandis (d) P.pyrifolia . 
plantations and the lowest for $P$. pyrifolia ( 0.34 tons/ha) under agri-horticulture based land use system. The leaf litterfall under $P$. deltoides was significantly higher (5\% level of significance) than the other tree species under investigation. It ranged from 0.34 to 7.8 tons/ha and the leaf litter fall followed the order $P$. deltoides $>T$. grandis $>$ E. tereticornis $>$ P. pyrifolia.

The highest litterfall under $P$. deltoides canopy could be due to its deciduous nature and luxurious growth of foliage. Chauhan et al., (2012) also reported that Poplar tree have maximum foliage during the summer season and due to its deciduous nature shed whole foliage during winter months in Punjab. It may be noted that deciduous tree species shed most of their leaves once in a year and the seasonality of this litterfall was affected by climatic conditions. Apart from the climatic factors soil type, elevation, stand age and level of disturbance also influence the litter production. The observed seasonal differences in leaf biomass production in our study might be related to microclimate extremes and/or changes in plant phenology (Palma et al., 2000). Das and Chaturvedi (2005) reported that total annual litter fall in poplar was between 1.95 and 10.00 Mg ha ${ }^{-1} \mathrm{yr}^{-1}$, of which 92-94 per cent was contributed by leaf litter. Wang et al., (2008) reported that broadleaved tree (Michelia macclurei) in combination of coniferous tree (Cunninghamia lanceolata) could increase litter production, nutrient return and thus help in restoration of soil fertility and sustainable land management in southern China.

Leaf litter decomposition: During the present study, temporal changes in dry weight (gm) and per cent weight loss in litter per bag were studied and the results showed that there was a continuous decrease in the dry weight of leaf litter with the passage of time in all the studied species (Table 1). Initially decomposition rate was slow up to February and increased thereafter. Litter decomposition is expressed as loss of dry matter at the end of each month. In $P$. pyrifolia, total leaf litter decomposed in ten months while in case of poplar and teak, $97.67 \%$ and $99 \%$ decomposition takes place within 10 months whereas in Eucalyptus only $87.70 \%$ leaf decomposed in ten months. For all the species, a biphasic pattern was observed in decomposition process, an initial phase (for 2-3 months) with slow rate of decomposition followed by rapid phase. A significant difference (at $5 \%$ level of significance) for decomposition was noticed after February month. Eucalyptus, leaf litter on the other hand took longer time for decomposition as compared to other three species. Pandey and Singh (1982) also reported the temporal variation in loss of dry matter during decomposition of leaves of Daphne cannabina and Cupressus torulosa. They reported that D. cannabina decomposed faster while $C$. torulosa decomposed most slowly. They also reported that climatic variations, chemical composi-

Table 1. Dry weight loss (gms) of leaf litters of different trees after different periods of incubation.

\begin{tabular}{|c|c|c|c|c|c|}
\hline \multirow[t]{2}{*}{ Months } & \multicolumn{4}{|c|}{ Tree species } & \\
\hline & P. deltoides & P. pyrifolia & E. tereticornis & T. grandis & $\operatorname{LSD}(p=0.05)$ \\
\hline January & 0.95 & 0.74 & 0.71 & 0.99 & NS \\
\hline February & 1.19 & 1.09 & 1.02 & 1.43 & NS \\
\hline March & 5.24 & 5.08 & 3.63 & 5.37 & 1.06 \\
\hline April & 6.43 & 5.97 & 4.75 & 6.67 & 1.21 \\
\hline May & 7.00 & 6.48 & 5.38 & 7.25 & NS \\
\hline June & 8.58 & 8.18 & 6.87 & 8.47 & 1.16 \\
\hline July & 9.15 & 8.70 & 7.88 & 9.26 & 1.01 \\
\hline August & 10.94 & 10.56 & 8.45 & 10.29 & 0.86 \\
\hline September & 13.85 & 13.68 & 11.78 & 14.11 & 1.21 \\
\hline October & 14.65 & - & 13.15 & 14.85 & 0.10 \\
\hline November & - & - & 13.30 & - & - \\
\hline
\end{tabular}

Table 2. Linear regression analysis for percent weight loss per month and climatic variables.

\begin{tabular}{|c|c|c|c|c|}
\hline \multirow{2}{*}{$\begin{array}{l}\text { Characters } \\
\text { Tree species/ climatic variables } \\
\end{array}$} & \multicolumn{2}{|c|}{$\begin{array}{l}\text { Linear regression equation } \\
X=\text { temperature }\left(C^{0}\right) \\
Y=\text { per cent weight loss/month }(\mathrm{mm})\end{array}$} & $\mathbf{r}^{2}$ & \multirow[b]{2}{*}{ Rainfall } \\
\hline & Temperature & Rainfall & Temperature & \\
\hline E. tereticornis & & & 0.177 & 0.079 \\
\hline P. deltoides & $Y=1.620 x+8.43$ & $Y=0.076 x+40.65$ & $(1.72)$ & $\begin{array}{l}(0.69) \\
0.210\end{array}$ \\
\hline P. pyrifolia & $Y=2.720 x-13.74$ & $Y=0.127 x+41.12$ & $0.471(7.12)^{*}$ & $\begin{array}{l}(2.13) \\
0.197\end{array}$ \\
\hline \multirow[t]{2}{*}{ T. grandis } & $Y=2.720 x-13.74$ & $Y=0.127 x+41.12$ & $0.425(5.91)^{*}$ & $\begin{array}{l}(2.00) \\
0.222\end{array}$ \\
\hline & $Y=2.646 x-11.48$ & $Y=0.130 x+41.42$ & $0.452(6.60)^{*}$ & $(2.28)$ \\
\hline
\end{tabular}

Values in parenthesis $\mathrm{f}$ value calculated; *Values significant at $5 \%$ level of significance 
Table 3. Nutrient composition of leaf litter of different tree species.

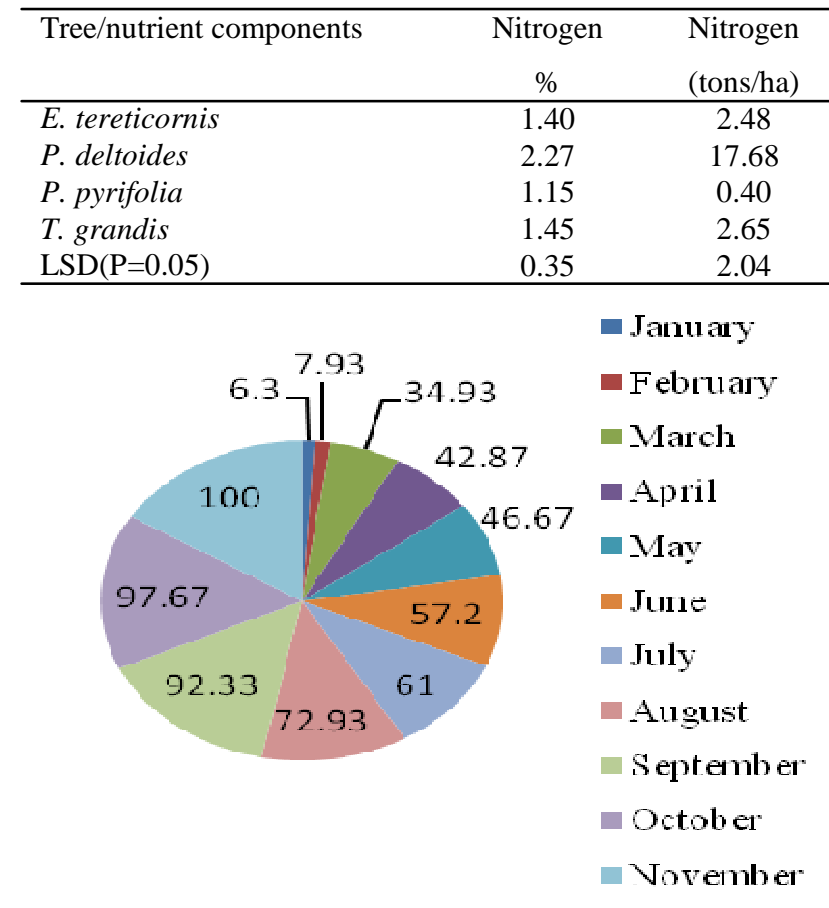

(a)

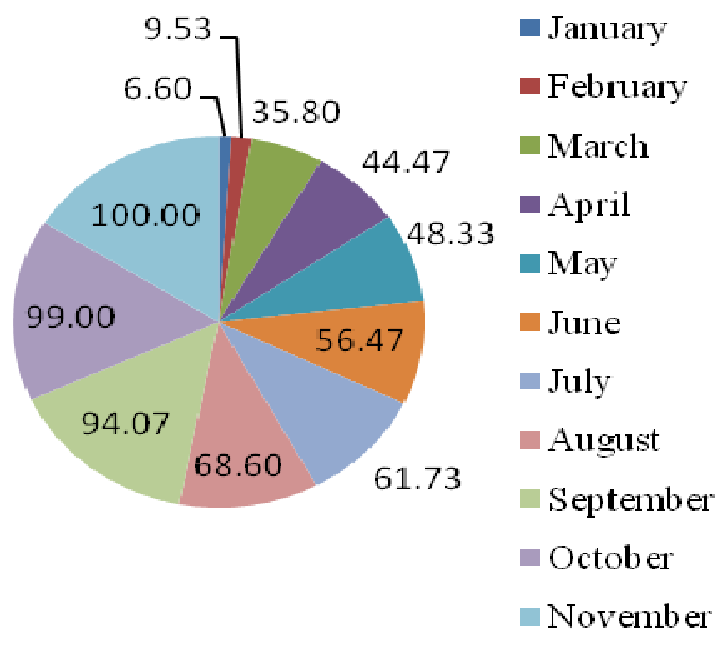

(c)

\begin{tabular}{cccc}
$\begin{array}{c}\text { Potassium } \\
\%\end{array}$ & $\begin{array}{c}\text { Potassium } \\
\text { (tons/ha) }\end{array}$ & $\begin{array}{c}\text { Phosphorus } \\
\%\end{array}$ & $\begin{array}{c}\text { Phosphorus } \\
\text { (tons/ha) }\end{array}$ \\
\hline 0.21 & 0.37 & 1.27 & 2.25 \\
0.31 & 2.42 & 1.90 & 14.82 \\
0.27 & 0.09 & 1.35 & 0.46 \\
0.32 & 0.59 & 1.57 & 2.87 \\
0.05 & 0.25 & 0.31 & 1.03 \\
\hline
\end{tabular}

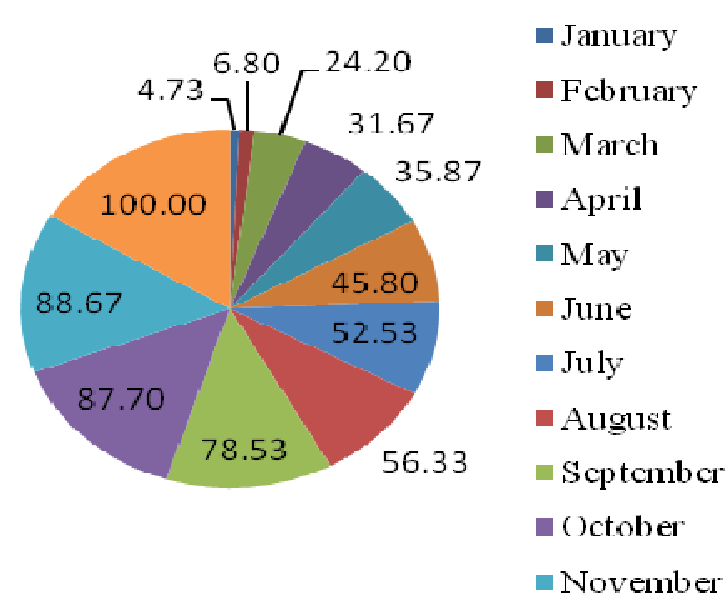

(b)

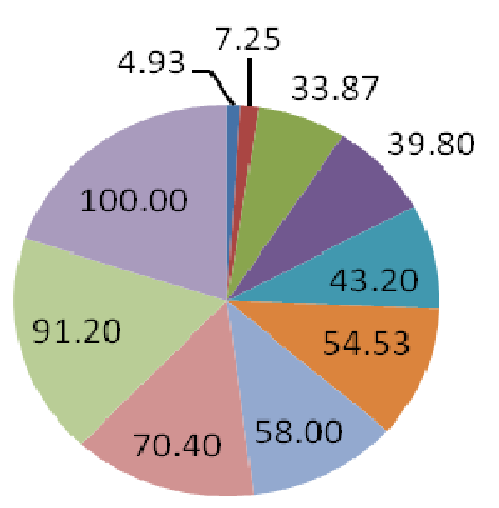

- January
- February
- March
- April
- May
June
July
August
September
October

(d)

Fig. 3. Percentage loss of dry matter in decomposing leaf litter of different tree species- (a) P. deltoides (b) Eucalyptus plantation (c) T. grandis (d) P. pyrifolia

tion of plant material, its palatability to soil fauna etc. mainly responsible for this temporal variation. During the present study the four species showed the following temporal order of decomposition after ten months: T. grandis $>$ P. deltoides $>$ P. pyrifolia $>$ E. tereticornis. Similarly Pandey (1999) showed the decomposition rate of four species in the following order: Shorea robusta (Sal),Tectona grandis (Teak), Eucalyptus spp. (eucalypts) and Pinus roxburghii (Pine) in Nainital, Uttarakhand, India.
The significant difference (5\% level of significance) in amount of weight loss in different months (Fig. 3) of the present study could be due to differences in the temperature and rainfall. Initial slow rate of decomposition till March can be ascribed to the low temperature and rainfall, which have resulted into low activity of decomposers. These results are similar to the results reported by Maithani et al., (1996); they also reported the slow rate of decomposition during winter season in disturbed subtropical humid forest in North-East India. 
After March, there was a gradual increase in decomposition rate till May month. This gradual increase reported in their study was attributed to late winter and early summer, which in combination with rising temperature resulted in limited stimulation of decomposition during summer season. With the further lapse of time, a rapid decomposition was observed in all the species and maximum weight loss occurred during these months in a disturbed subtropical humid forest of North-East India.

Bloomfield et al., (1993) concluded that the higher decomposition rates in leaf litter of Prestoea montana and Dacryodes excelsa in Puerto Rico may be attributed due to congenial effect of temperature on the activities of decomposers and may be stimulatory effect of frequent rain showers on leaching of water soluble substances and nonstructural carbohydrates. The positive and significant relation (5\% level of significance) of temperature with weight loss in the present study confirms the above findings. The more important role of temperature as compared to rainfall deduced from the regression analysis (Table 2). The nutrient content of the leaves also affects the rate of decomposition. Generally high levels of nutrients, notably nitrogen, are expected to be able to accelerate the decomposition process. Melillo et al., (1982) also reported the positive correlation between initial $\mathrm{N}$ concentration and the decomposition rate in hardwood tree species (Fagus grandifolia, Acer saccharum, Betula alleghaniensis, Fraxinus americana, Tilia americana, Acer rubrum, Betula papyrifera, Quercus borealis and Ulmus americana) in the Hubbard Brook Experimental Forest, New Hampshire, USA. Winter season have low temperature and soil moisture so less activity of decomposer organisms and also slower rate of decomposition process (Tripathi and Singh 1992). Bisht et al., (2014) also reported that the air temperature is a major determinant for litter decomposition in sub alpine forest communities of the Northwest Himalayas.

Nutrient characteristics of litter and $N, P$ and $K$ accretion to soil: Nitrogen (\%) input in different tree species followed the order: $P$. deltoides $>T$. grandis $>$ E. tereticornis $>P$. pyrifolia. Nitrogen composition of leaf litter of different tree species ranged from 1.15 to $2.27 \%$ (Table 3). Maximum input through leaf litter was in $P$. deltoides $(2.27 \%)$. Nitrogen $(\%)$ input in leaf of different tree species followed the order: $P$. deltoides $>T$. grandis $>E$. tereticornis $>P$. pyrifolia (Table 3).The $\mathrm{K}$ input (\%) was maximum in leaves of $T$. grandis (0.32) and minimum in E. tereticornis (0.21). The maximum input of $\mathrm{P}(\%)$ through leaf litter was in 5 year old $P$. deltoides (1.90) whereas, minimum value was observed in E. tereticornis (1.27) during the study period. The total annual nutrient content through total litter fall was low in E. tereticornis plantation. The amount of N, P and K returned through litter fall in $P$. deltoides, $T$. grandis and $P$. pyrifolia were greater than E. tereticornis tree species. However, Bargali et al. (1992) reported a much lower value (29.8 and 2.643.9 (kg ha- ${ }^{1} \mathrm{yr}^{-1}$, respectively) in Eucalyptus plantations in the Terai region of central Himalaya.

George (1982) reported that leaf litter of Eucalyptus contributed a major portion of the total $\mathrm{N}, \mathrm{P}$ and $\mathrm{K}$ in 5, 7 and 10 years old Eucalyptus hybrid plantations in East Dehradun Division, Uttarakhand. He reported that the total annual return of nutrients in all the three plantations is highest for $\mathrm{Ca}(49.2,42.8$ and $73.2 \mathrm{~kg} / \mathrm{ha})$ followed by $\mathrm{N}(29.8,32.1$ and $59.2 \mathrm{~kg} / \mathrm{ha}), \mathrm{K}(15.0$, 17.5 and $30.6 \mathrm{~kg} / \mathrm{ha}), \mathrm{Mg}(5.0,6.1$ and $9.3 \mathrm{~kg} / \mathrm{ha})$, and lowest for $\mathrm{P}(1.6,1.9$ and $3.9 \mathrm{~kg} / \mathrm{ha})$ respectively for 5 , 7 and 10 years old Eucalyptus hybrid plantation. During the present study, the order of relative abundance of nutrients through litter fall was $\mathrm{N}>\mathrm{K}>\mathrm{P}$ which also agrees with the findings of George (1982). Peterson and Rolfe (1982) in Floodplain and Upland Forests at Robert Allerton Park in central Illinois reported that foliage account for most of the $\mathrm{N}$ returned through litter. Tandon et al., (1991) in Populus deltoides plantations of Terai region in Uttar Pradesh, Lodhiyal et al., (2002) in poplar plantations of central Himalayas and Panwar (2003) in Yew (Taxus baccata) and Kharshu oak (Quercus semecarpifolia) forests of the Western Himalaya also observed that the return of nitrogen and potassium through litterfall was higher than the other nutrients $(\mathrm{Mg}$ and $\mathrm{Ca})$.

\section{Conclusion}

Tree based agroforestry land use systems help in improving the nutrient status of the soil through the production of litter. During the present study, litterfall in the selected tree species varied significantly during different months of the study period and there was marked variation in the amount of leaf litterfall across season and tree species. The present study showed that temperature as compared to rainfall play a significant role in litter decomposition, probably the temperature may provide congenial atmosphere for litter decomposers. The study also showed that the nutrient content in the litter especially nitrogen affects the rate of decomposition. Among the tree species studied, the short rotation poplar exhibited highest annual litter production, highest returns of $\mathrm{N}, \mathrm{P}$ and $\mathrm{K}$ levels via leaf litter and it is one of the species which takes lesser duration for litter decomposition. These characteristics make the poplar tree as one of the ideal agroforestry species for improving the soil fertility. T. grandis, E. tereticornis and $P$. pyrifolia based land use systems can also help in improving soil nutrient status as compared to traditional wheat and paddy based land use systems under this region of Punjab. Therefore tree based land use systems need to be promoted over the traditional field crops for realizing better environmental benefits in this region.

\section{REFERENCES}

Bargali, S. S. Singh, S. P. and Singh, R.P. (1992). Structure and 
functioning of age series of eucalyptus plantations in Central Himalaya 1. Dry matter dynamics; Annals of Botany 69: 405-411.

Bhardwaj, S. D. Panwarand Gautam, S. (2001). Biomass production potential and nutrient dynamics of Populus deltoides under high density plantations. Indian Forester 127: 144-153.

Bhat, N. S. and Jan, S. (2010). Litterfall and Nutrient Return in Ulmus villosa Forests of Dachigam National Park, Jammu and Kashmir. Research Journal of Agricultural Sciences 1 (4): 363-365.

Bisht, V. K. Bhagwati, P. Nautiyal, B. P. Chandra, P. Kuniyal, C. P, Prasad , P. and Rakesh, C. Sundriyal (2014). Litter Production, Decomposition, and Nutrient Release in Subalpine Forest Communities of the Northwest Himalaya Journal of Ecosystems Article ID 294867, 13 pp.

Bloomfield, J. Vogt, K. A. and Vogt, D. J (1993). Decay rate and substrate quality of fine roots and foliage of two tropical tree species in the Luquillo experimental forest, Puerto Rioo. Plant and Soil 150: 233-245.

Chauhan, S. K. Brar, M. S. and Sharma, R. (2012). Performance of poplar (Populus deltoides Marsh) and its effect on wheat yield under agroforestry system in irrigated agroecosystem, India Caspian Journal of Environmental Sciences 10(1): 53-60.

Das, D.K. and Chaturvedi, O.P. (2005). Structure and function of Populus deltoides agroforestry systems in eastern India: 1. Dry matter dynamics. Agroforestry Systems 65: 215 -221 .

Dhillon W.S., S.K. Chauhan, N. Jabeen, C. Singh and N. Singh (2012). Growth Performance of Intercropping System Components and Nutrient Status of Soil under Hortisilvicultural System. International Journal of Environment and Resource 1(1): 31-38.

George, M. (1982). Litter production and nutrient return in Eucalyptus hybrid plantations. Indian Forester 108: 253 260.

Gomez, K. A. and Gomez, A. A. (1984). Statistical procedures for agricultural research $2^{\text {nd }}$ ed. John Willey and sons, New York, $680 \mathrm{pp}$.

Jackson, M. L. (1973). Soil Chemical Analysis. Prentice Hall of India Pvt Ltd., New Delhi.

Kaushal, R. Verma K. S. and Singh K. N. (2005). Seasonal dynamics and role of substrate quality in leaf litter decomposition of different agroforestry tree species. Indian Journal of Agroforestry 7(1): 44-50.

Lodhiyal, L. S. Lodhiyal, N. and Sing, S. K. (2002). Litter dynamics and nutrient return of poplar plantations in moist plain areas of central Himalayas. Indian Forester 128: 1183-1194.

Maithani, K. Tripathi, R. S, Arunachalam, A. and Pandey, H .N. (1996). Seasonal dynamics of microbial C, N and during regrowth of a disturbed subtropical humid forest in northeast India. Applied Soil Ecology 4: 31-37.

Melillo, J. M. Aber, J.D. and Muratore, J. F. (1982). Nitrogen and lignin control of hardwood leaf litter decomposition dynamics. Ecology 63: 621-626.

Moshin, F. Singh, R. P. and Singh, K. (1996). Nutrient cycling of poplar plantation in relation to stand age in agroforestry system. Indian Journal of Forestry 19: 302-310.

Palma, R. M. Defrieri, R. L. Tortarolo, M. F. Prause, J. and Gallardo, J. F. (2000). Seasonal changes of bio-elements in the litter and their potential return to green leaves in four species of the Argentine subtropical forest. Annals of Botany (Lond) 85:181-186. doi:10.1006/anbo.1999.1005.

Pandey R.R., Sharma G., Tripathi S.K., A.K. Singh (2007) Litterfall, litter decomposition and nutrient dynamics in a subtropical natural oak forest and managed plantation in northeastern India. Forest Ecology and Management 240 (1-3): 96-104.

Pandey, P. K. (1999). Litter decomposition in tropical plantations: impact of climate and substrate quality. Indian Forester 125: 599-608.

Pandey, U. and Singh, J. S. (1982). Leaf litter decomposition in an oak conifer forest in Himalaya: the effects of climate and chemical composition. Forestry 55(1): 47-59.

Panwar, V. P. (2003). Studies on litter production, decomposition and nutrient release in Yew (Taxus baccata) and Kharshu oak (Quercus semecarpifolia) forests of the Western Himalayas. Ph.D thesis, Department of Bio Science, Himachal Pradesh University, Summer Hills, Shimla.

Peterson, D.L. and Rolfe, G. L. (1982). Nutrient dynamics and decomposition of litterfall in flood-plain and upland forest of Central Illinois; Forest Science 28: 667-681.

Piper, C. S. (1966). Soil and Plant analysis. pp 368. Hans Publisher. Bombay.

Pratt, P. F. (1982). Potassium Chemical and Microbiological properties. In Page A L, Miller R H and Kenney D R (ed). Methods of soil analysis. Agron. soil soc. Am. Madison, Wisconsin, USA, 225-46 pp.

Singh and Sharma (2012). Depthwise distribution of soil organic carbon and nutrients under some tree species after seventeen years of plantation. Journal of the Indian Society of Soil Science 60(3):198-203.

Singh, B. (1998). Biomass production and nutrient dynamics in three clones of Populus deltoides planted on Indo-Gangetic plain. Plant Soil 203: 15-26.

Singh B. (2009) Return and Release of Nutrients from Poplar Litterfall in an Agroforestry System under Subtropical Condition. Journal of the Indian Society of Soil Science 57 (2): 214-218.

Spark, D. L. Page, A. L. Helmke, P. A. Leoppert, R. H. Soltanpour, P.N. Tabatabai, M. A. and Summer, M. E. (ed) (1996). Method of Soil Analysis, part 3. American Society of Agronomy Inc, Madison, Wisconsin, USA.

Swift, M. J. Heal, O. W. and Anderso, J. M. (1979). Decomposition in terrestrial ecosystems. In: Studies in Ecology. University of California Press, Berkeley, USA. Vol.5, 4687pp.

Tandon, V .N. Pandey, M. C. Rawat, H. S. and Sharma, D. C. (1991). Organic productivity and mineral cycling in plantations of Populus deltoides in Terai region of Uttar Pradesh. Indian Forester 117: 596-608.

Tripathi, S. K. and Singh, K. P. (1992). Abiotic and litter quality control during the decomposition of different plant parts in dry tropical bamboo savanna in India. Pedobiologia 36:241-256.

Wang, Q. Wang, S. Huang, Y. (2008). Comparisons of litterfall, litter decomposition and nutrient return in a monoculture Cunninghamia lanceolata and a mixed stand in southern China. Forest Ecology and Management 255:1210-1218.

Yadav, V. and Malanson, G. (2007). Progress in soil organic matter research: litter decomposition, modelling, monitoring and sequestration, Progress in Physical Geogra- 